\title{
Metalated Nitriles: Cation-Controlled Cyclizations
}

\author{
Fraser F. Fleming, ${ }^{*}$ Yunjing Wei, Wang Liu, and Zhiyu Zhang \\ Department of Chemistry and Biochemistry, Duquesne University, Pittsburgh, \\ Pennsylvania 15282-1530
}

Supporting Information Table of Contents

S2




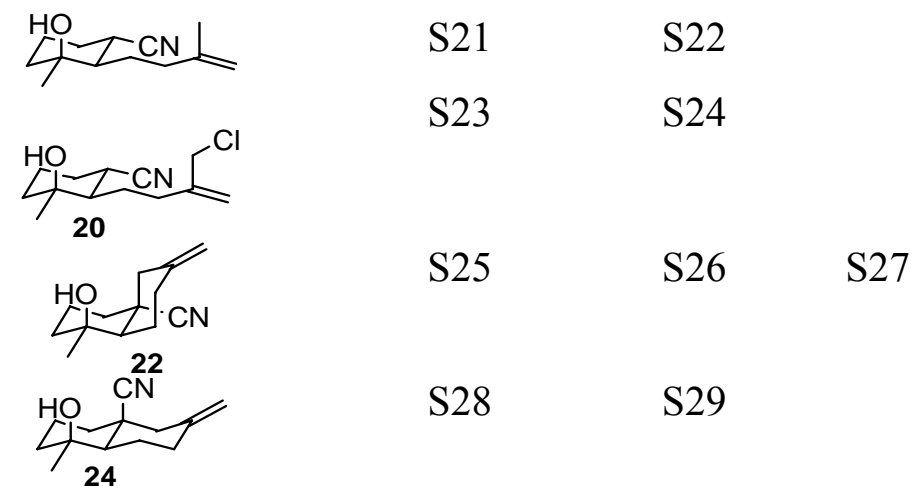


General Deprotonation - Cyclization Procedure with i-PrMgCI: A THF solution (3 equivalence) of $i$-PrMgCl was added dropwise to a room temperature THF solution of $\boldsymbol{\gamma}$ hydroxy nitrile. After $1.5 \mathrm{~h}$, saturated, aqueous, $\mathrm{NH}_{4} \mathrm{Cl}$ was added, the aqueous phase was extracted with EtOAc, and the combined organic extracts were washed with brine, dried $\left(\mathrm{Na}_{2} \mathrm{SO}_{4}\right)$, and concentrated. Purification by radial chromatography afforded pure material for further characterization.

General Deprotonation - Cyclization Procedure with BuLi: A hexanes solution (2.1-3.0 equivalence) of BuLi was added, dropwise, to a $-78{ }^{\circ} \mathrm{C}$, THF solution of of $\boldsymbol{\gamma}$ hydroxy nitrile. After $2 \mathrm{~h}$, the mixture was allowed to warm to room temperature and after a further $1.5 \mathrm{~h}$, an aqueous solution (3 equivalence) of $\mathrm{TsOH} \cdot \mathrm{H}_{2} \mathrm{O}$ was added. After 15 min, brine was added and the mixture was extracted with EtOAc. The combined organic extracts were washed with brine, dried $\left(\mathrm{Na}_{2} \mathrm{SO}_{4}\right)$, and concentrated to afford the crude product that was purified by radial chromatography. 

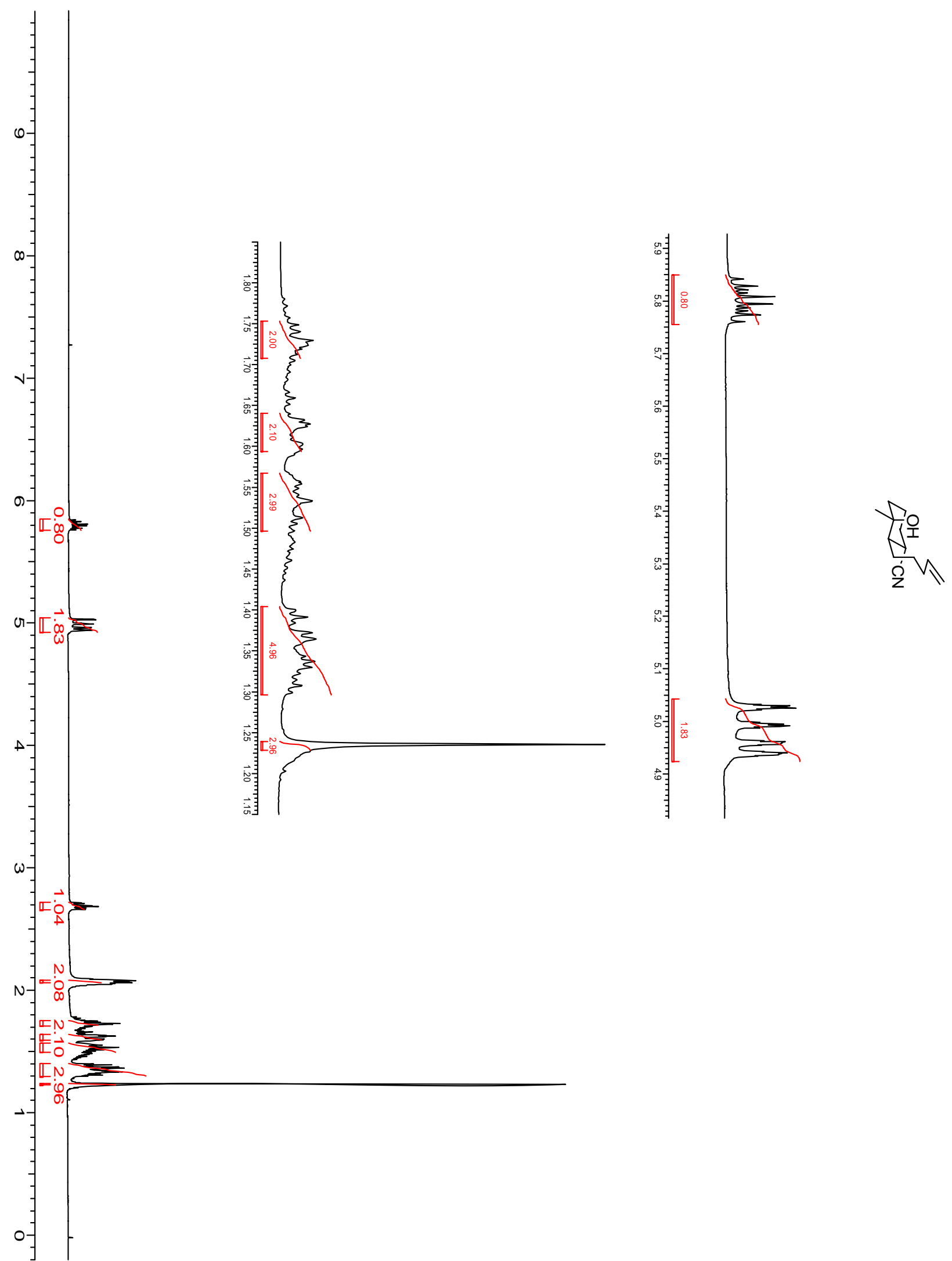


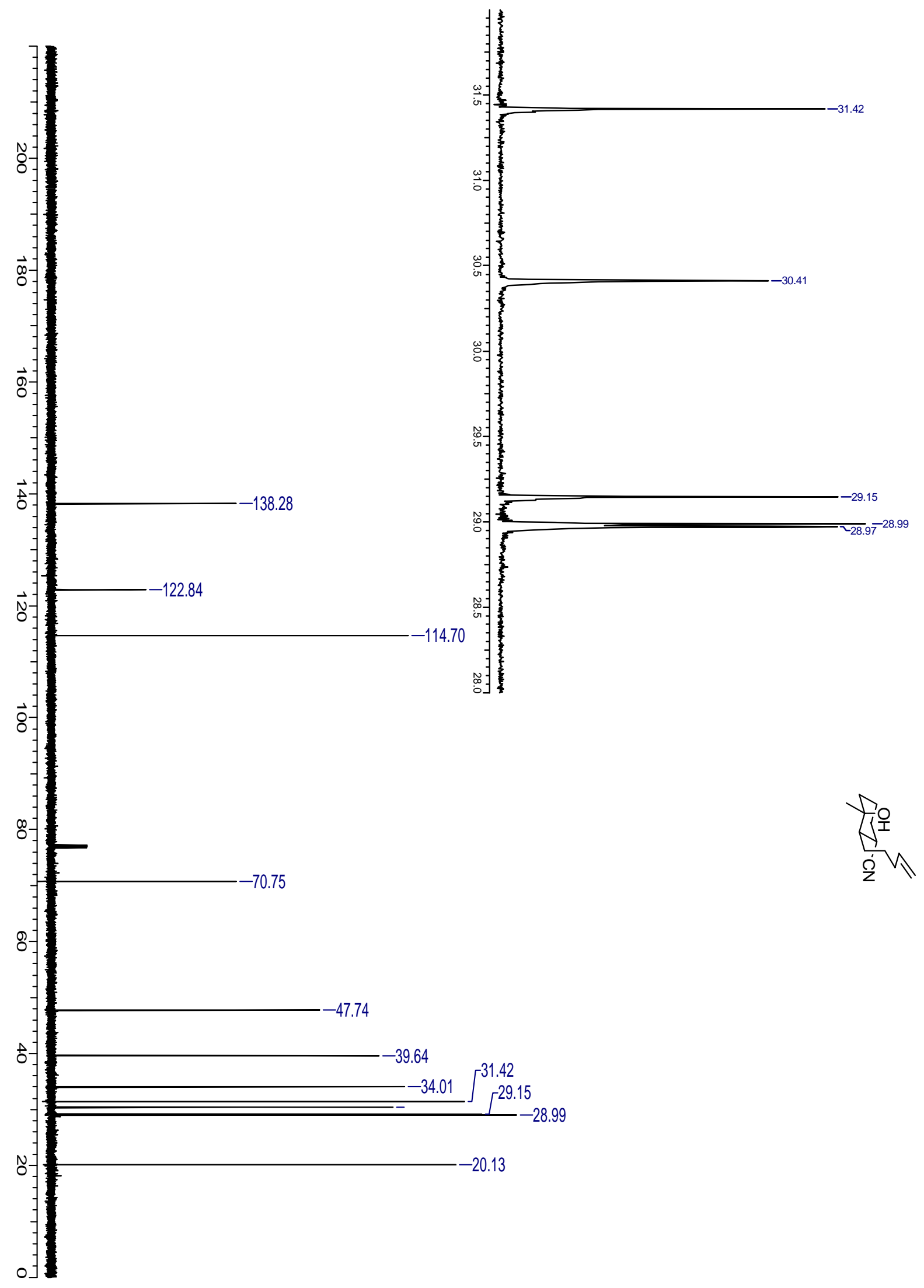




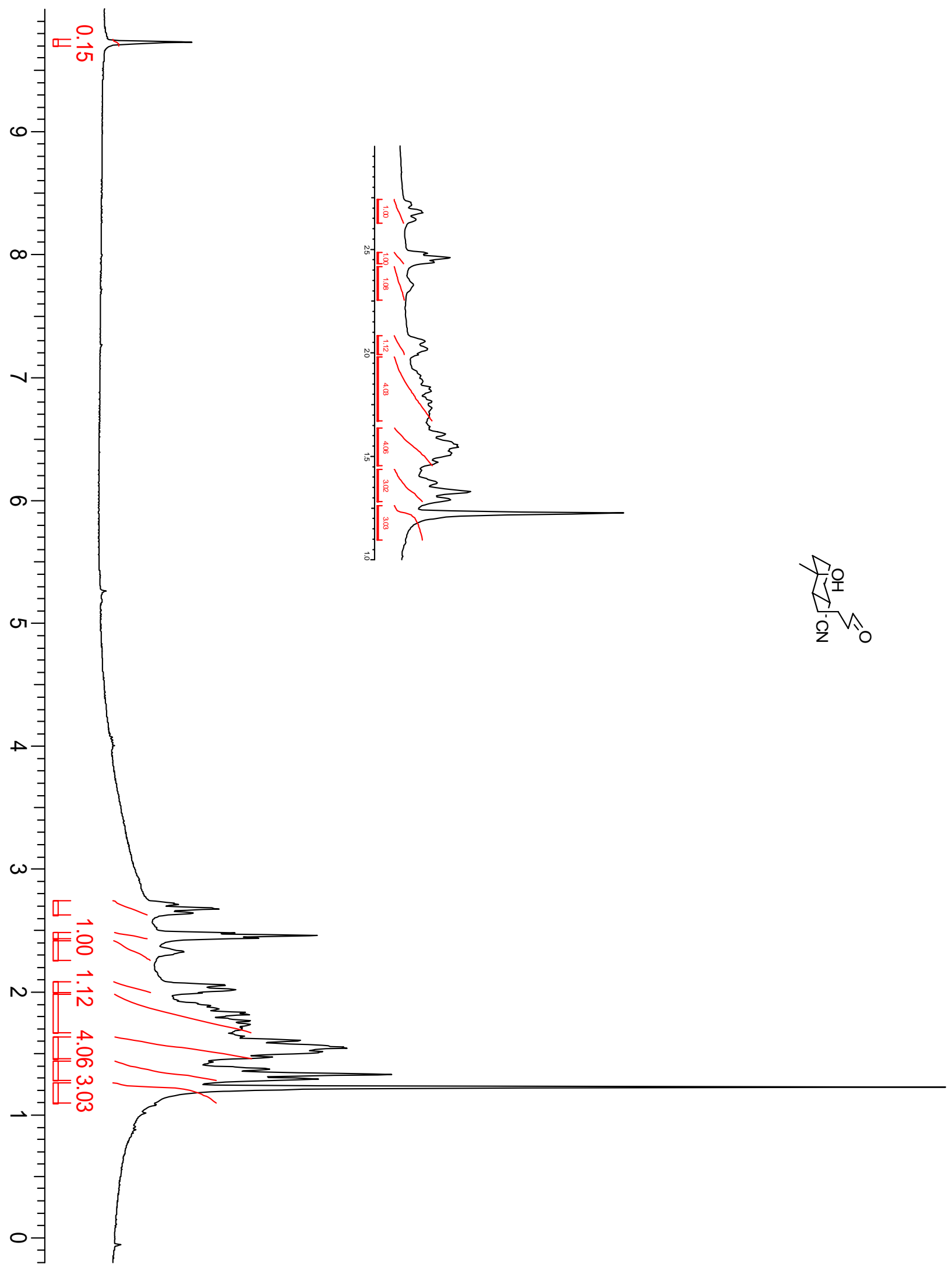




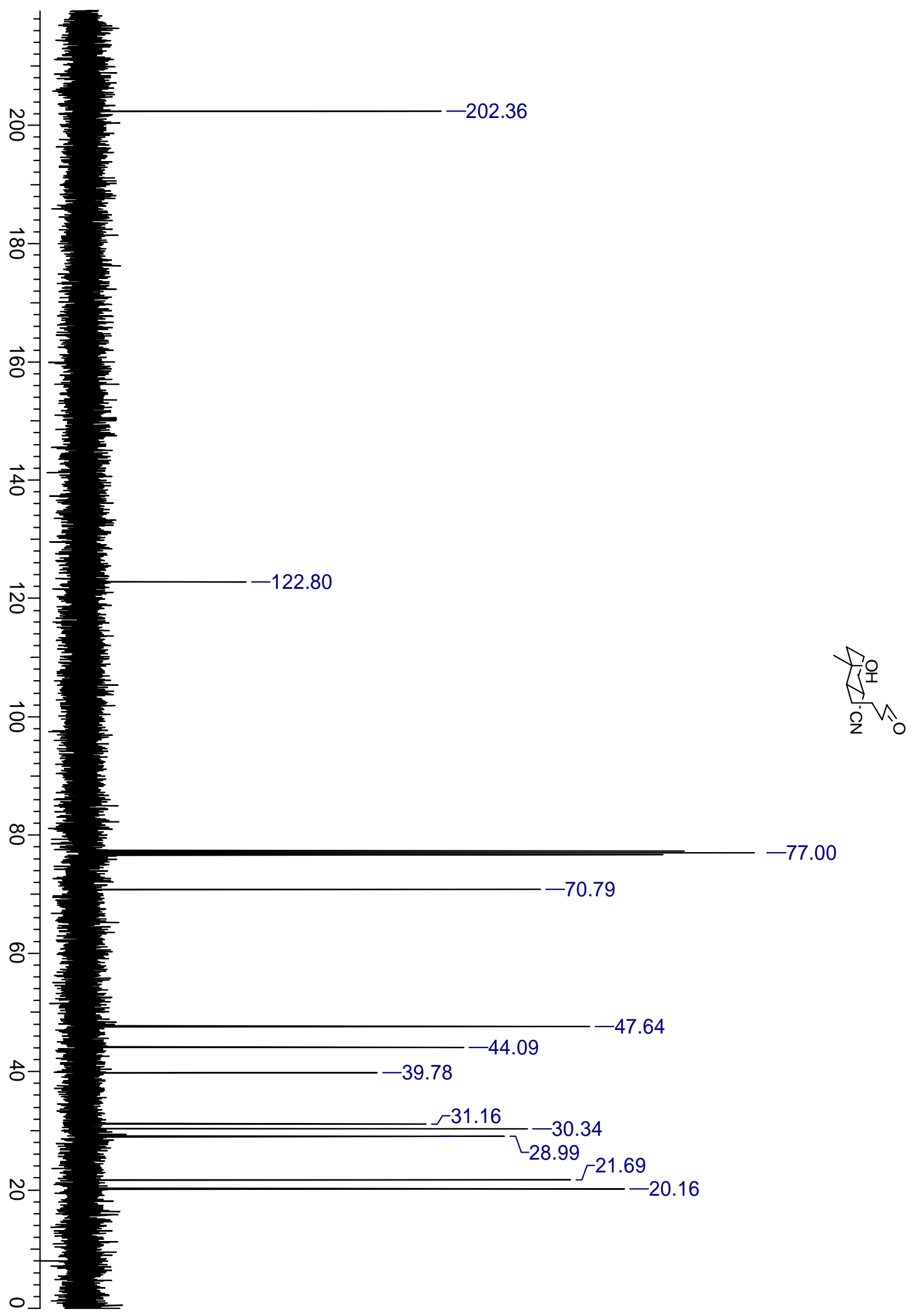




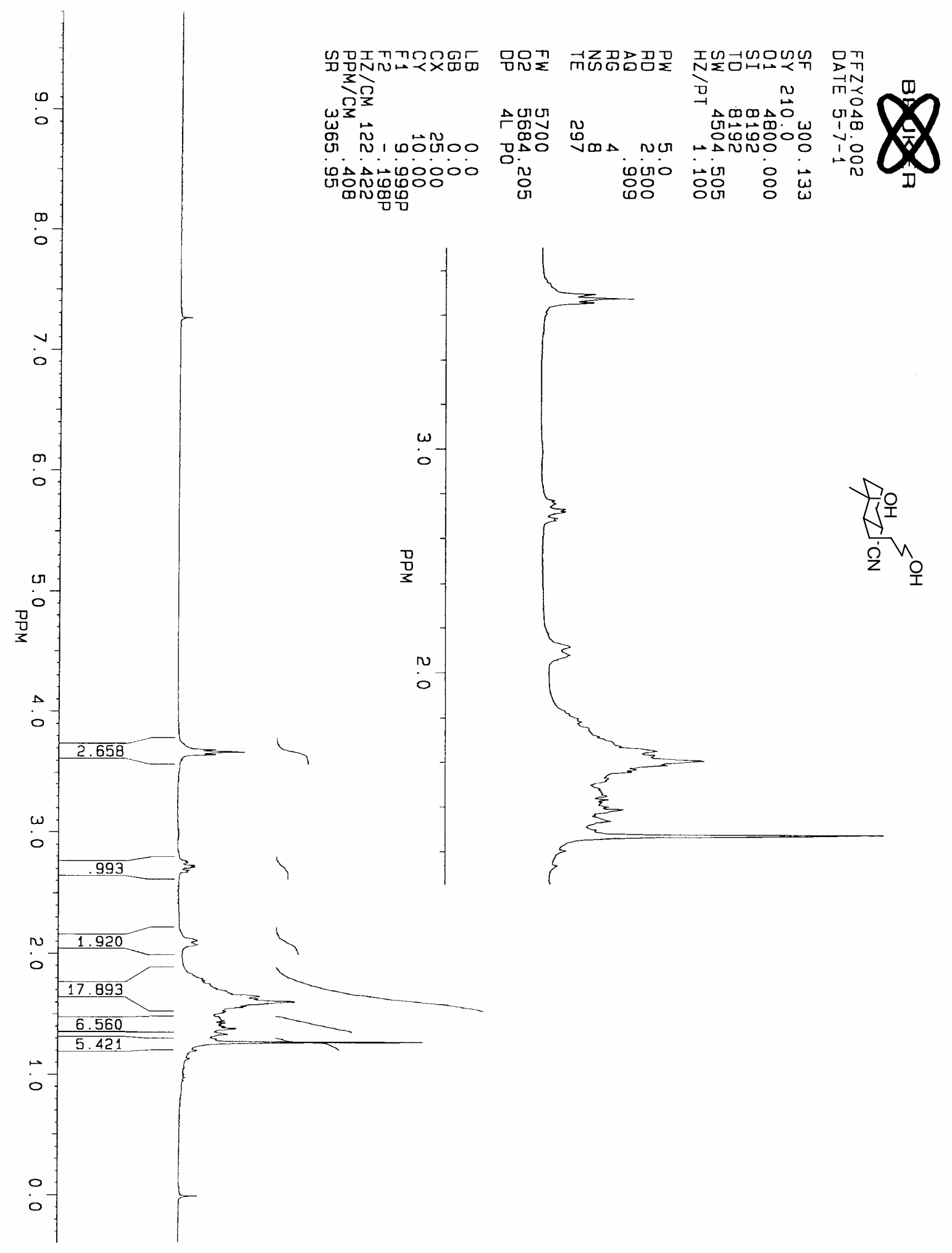




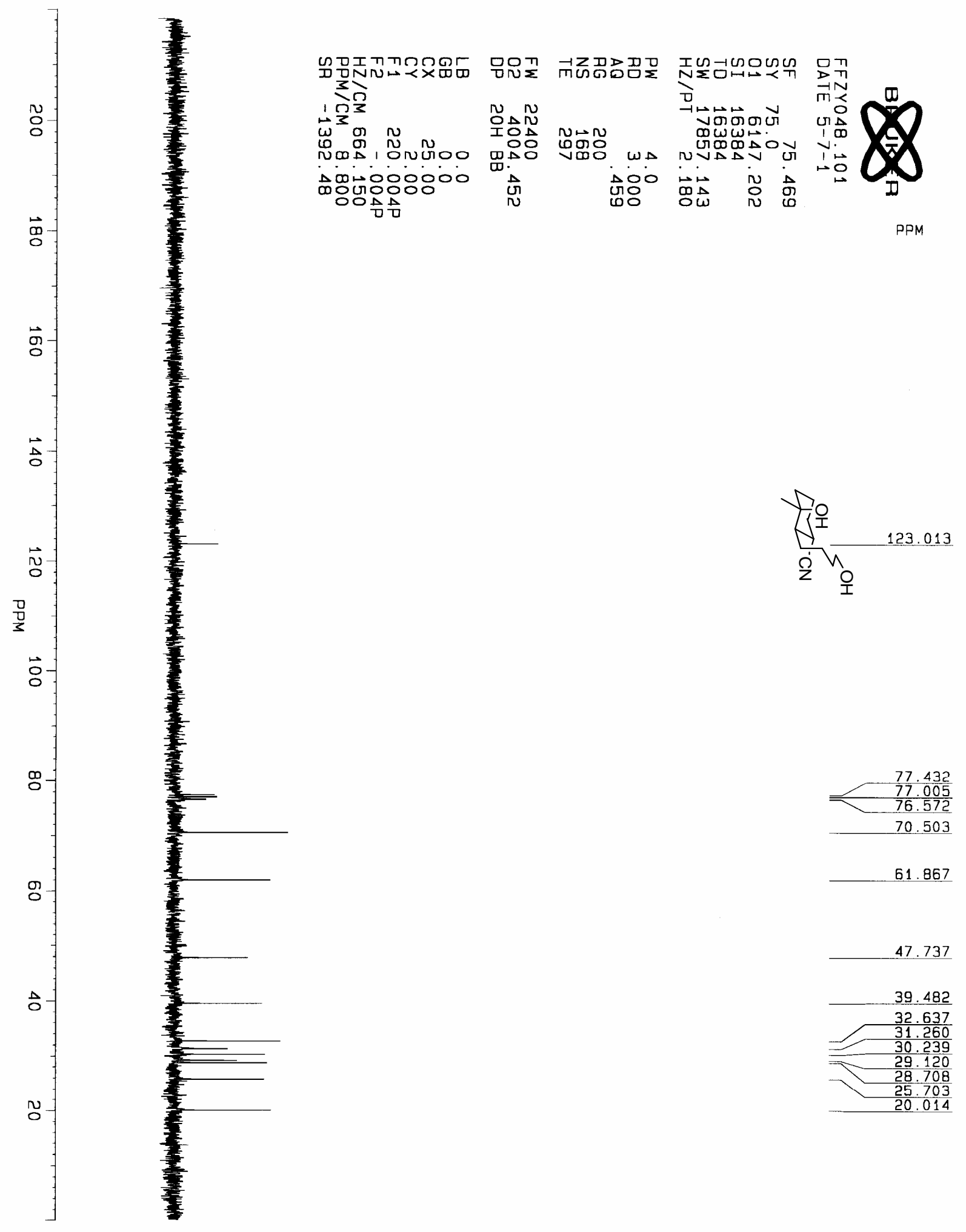



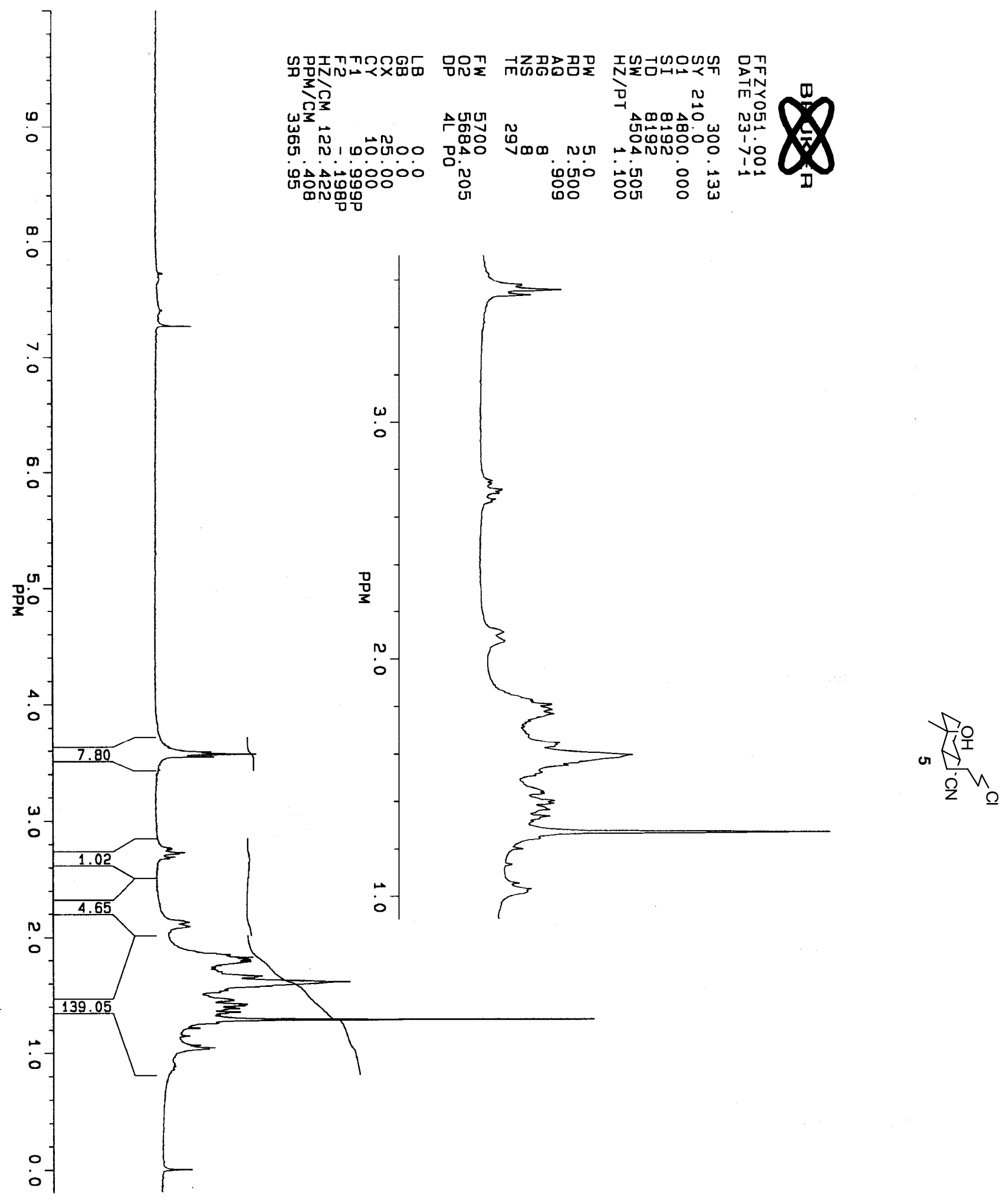


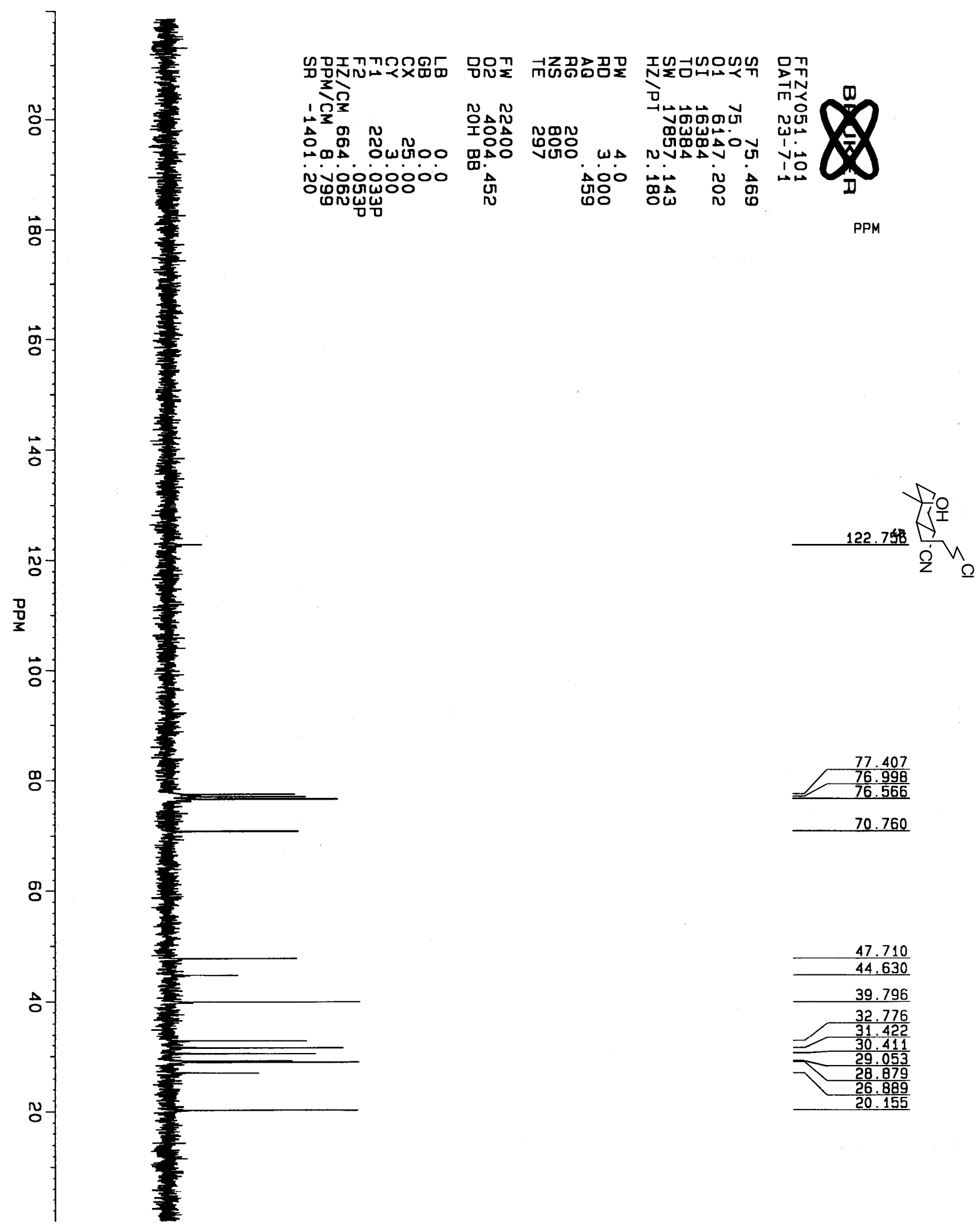




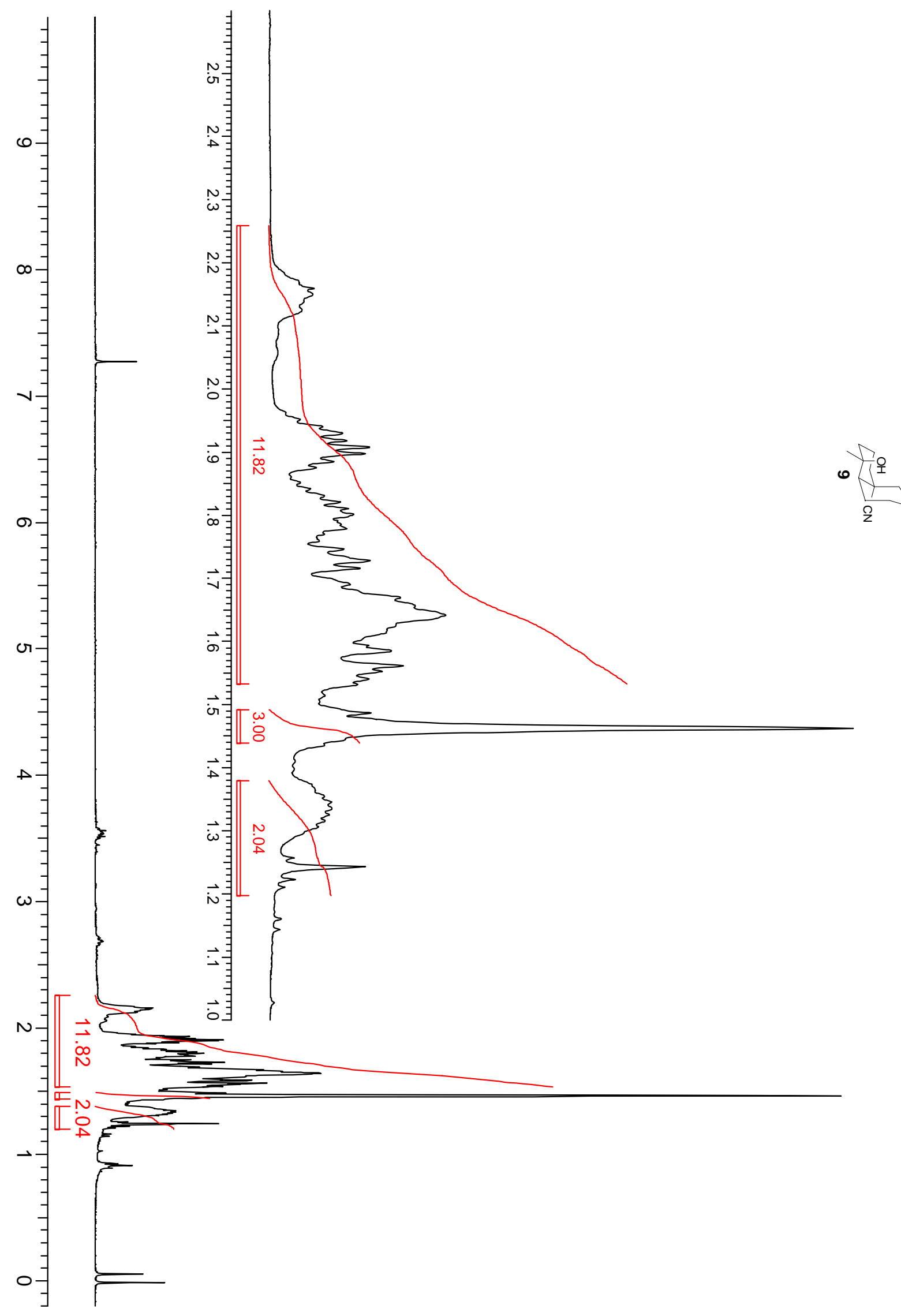




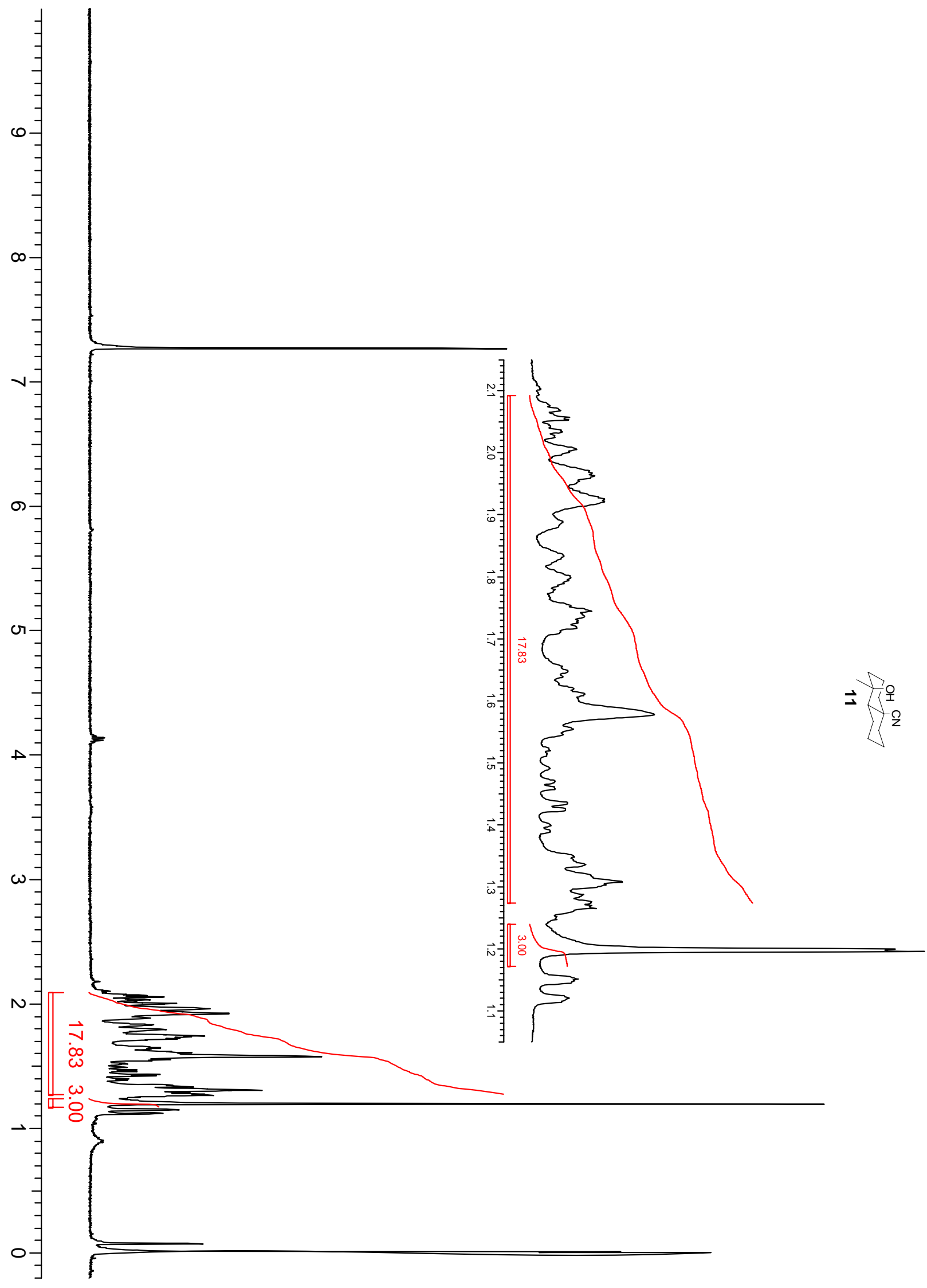




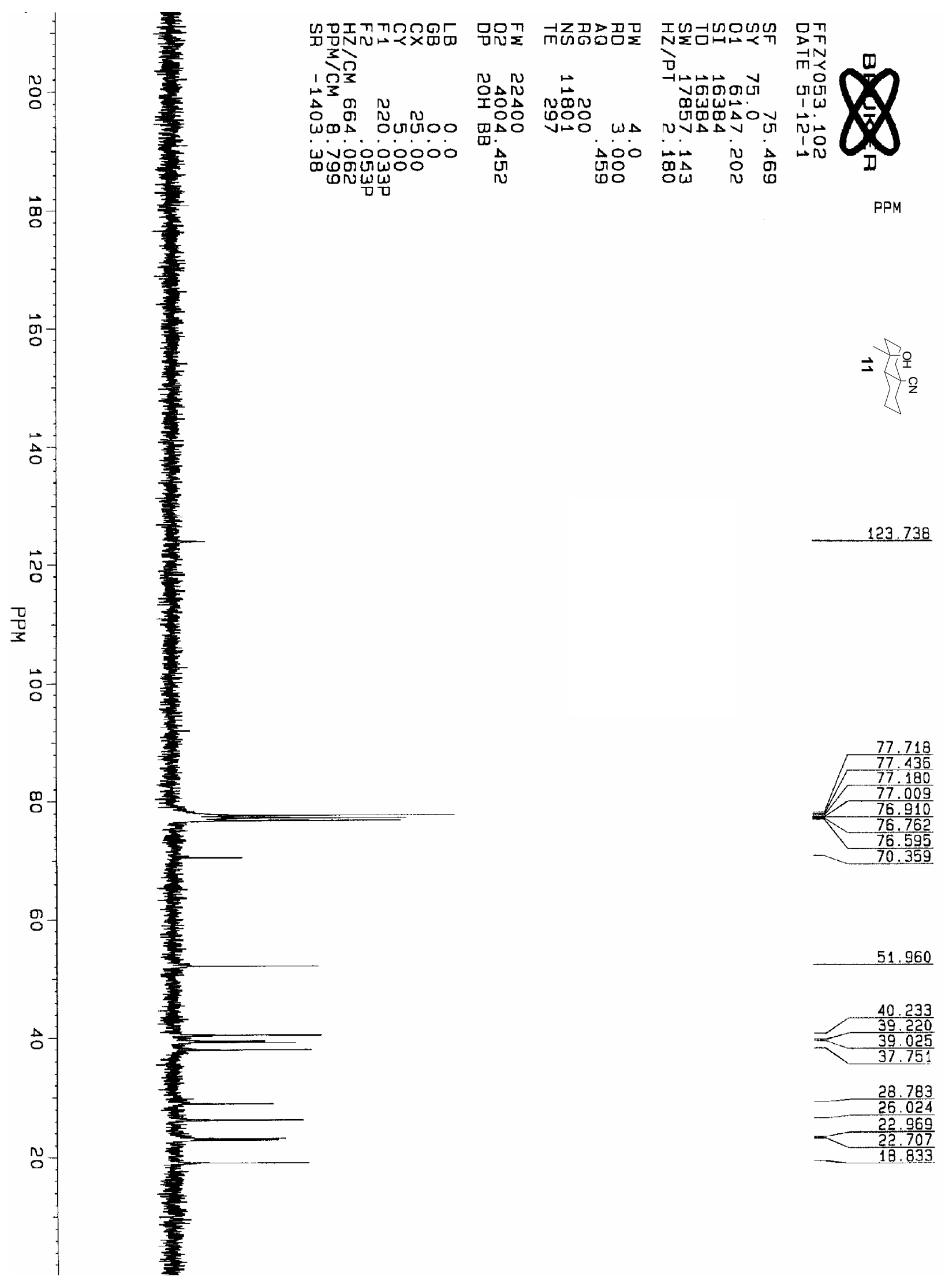




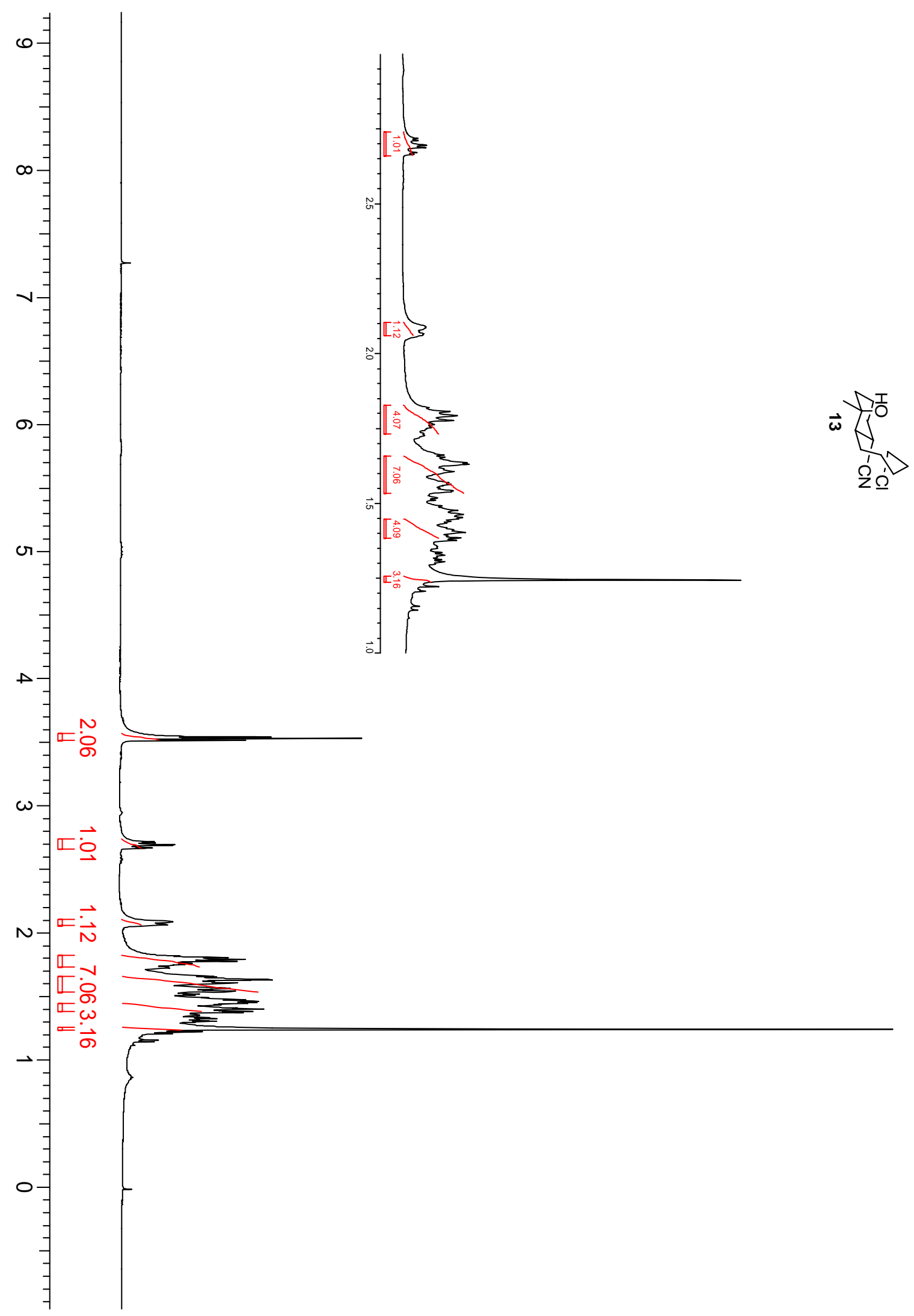




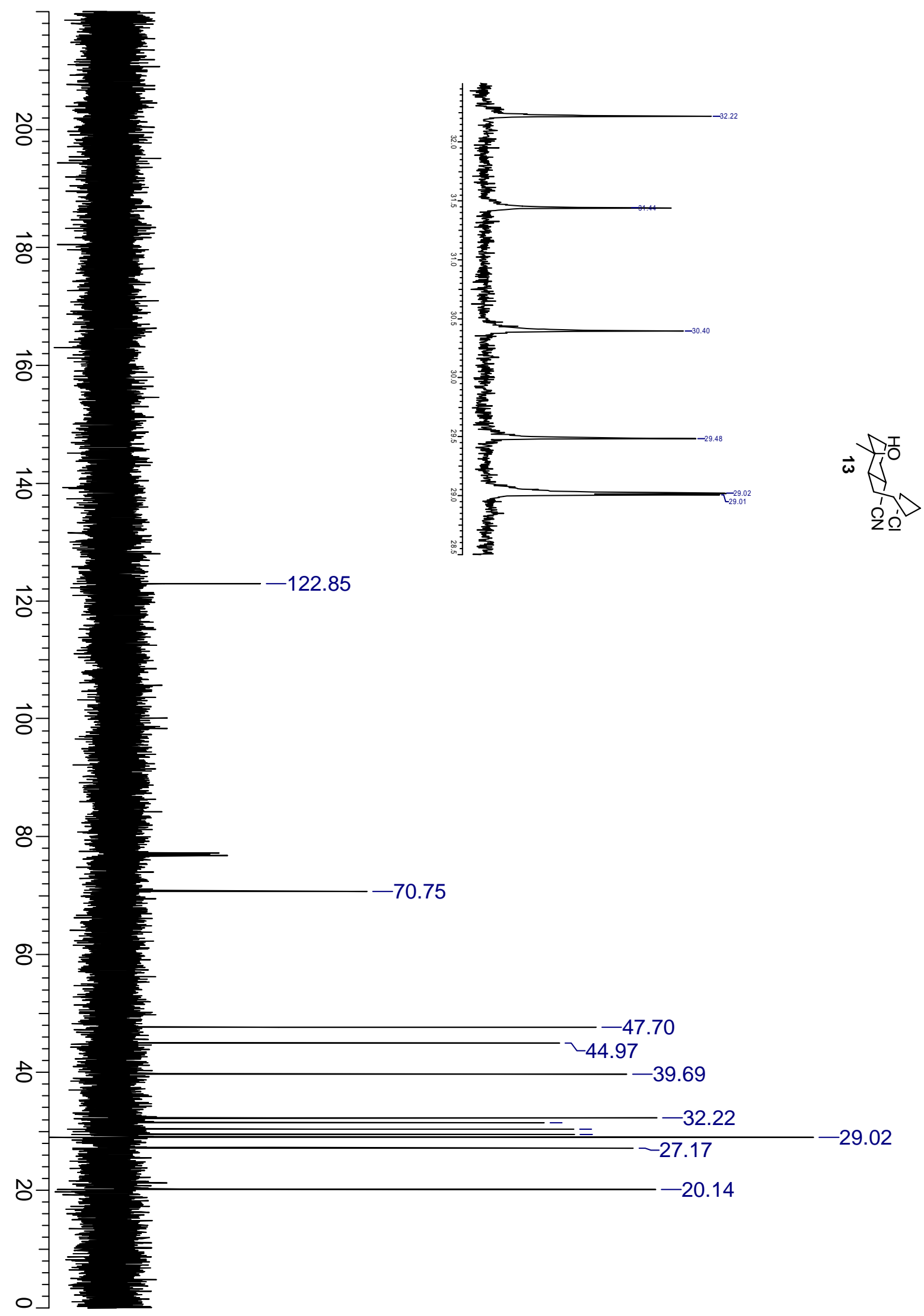




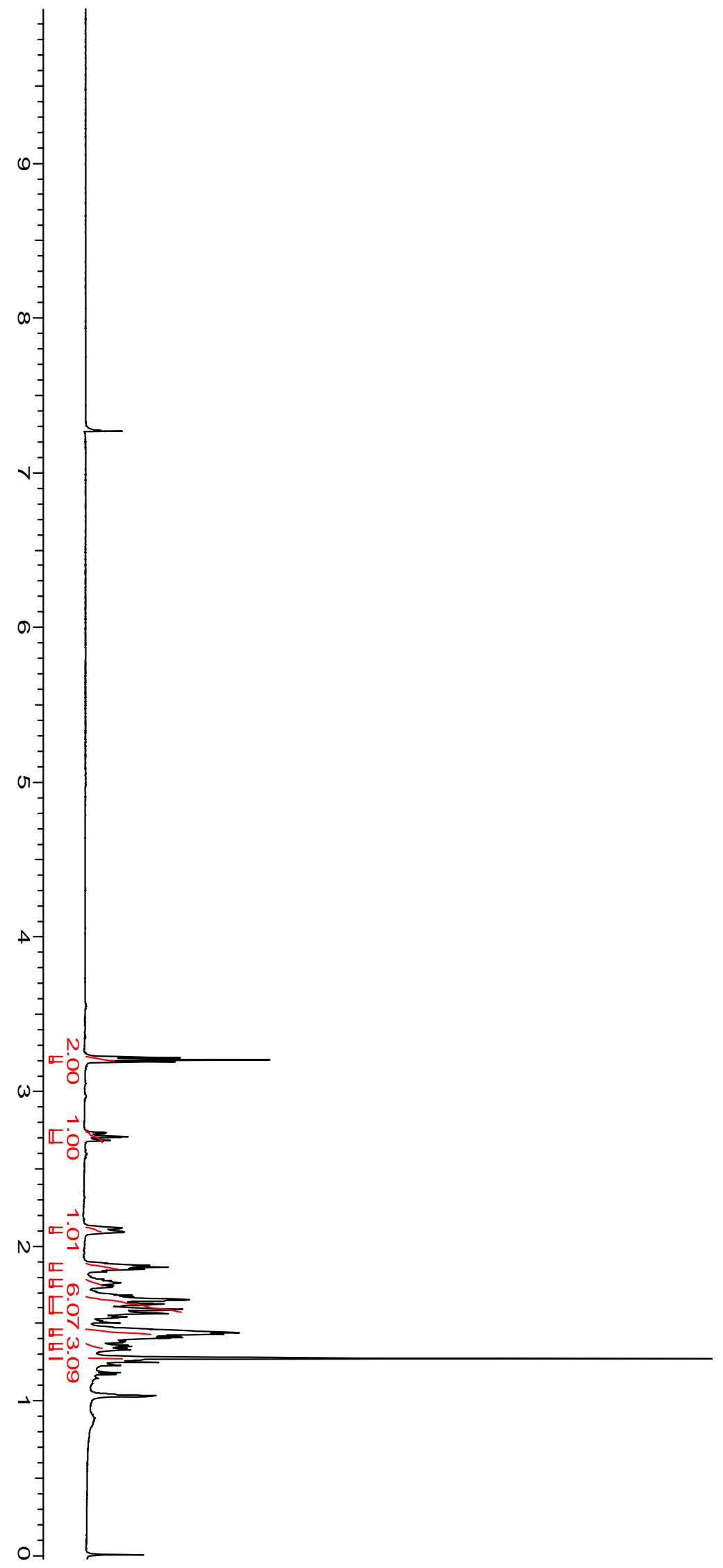

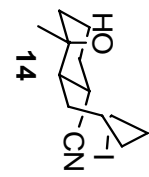




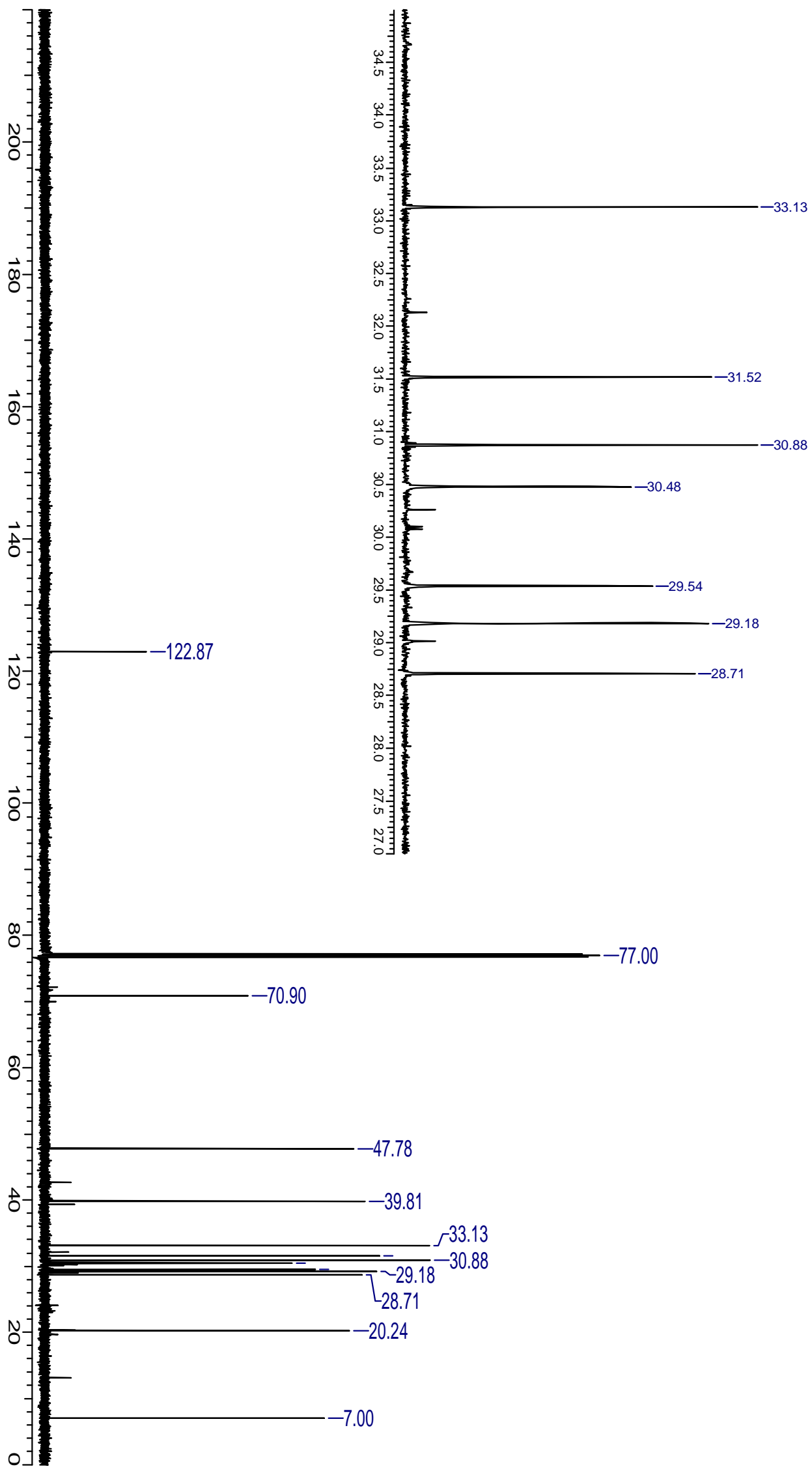

$5 \int_{\substack{1 \\ 0}}^{1}$ 


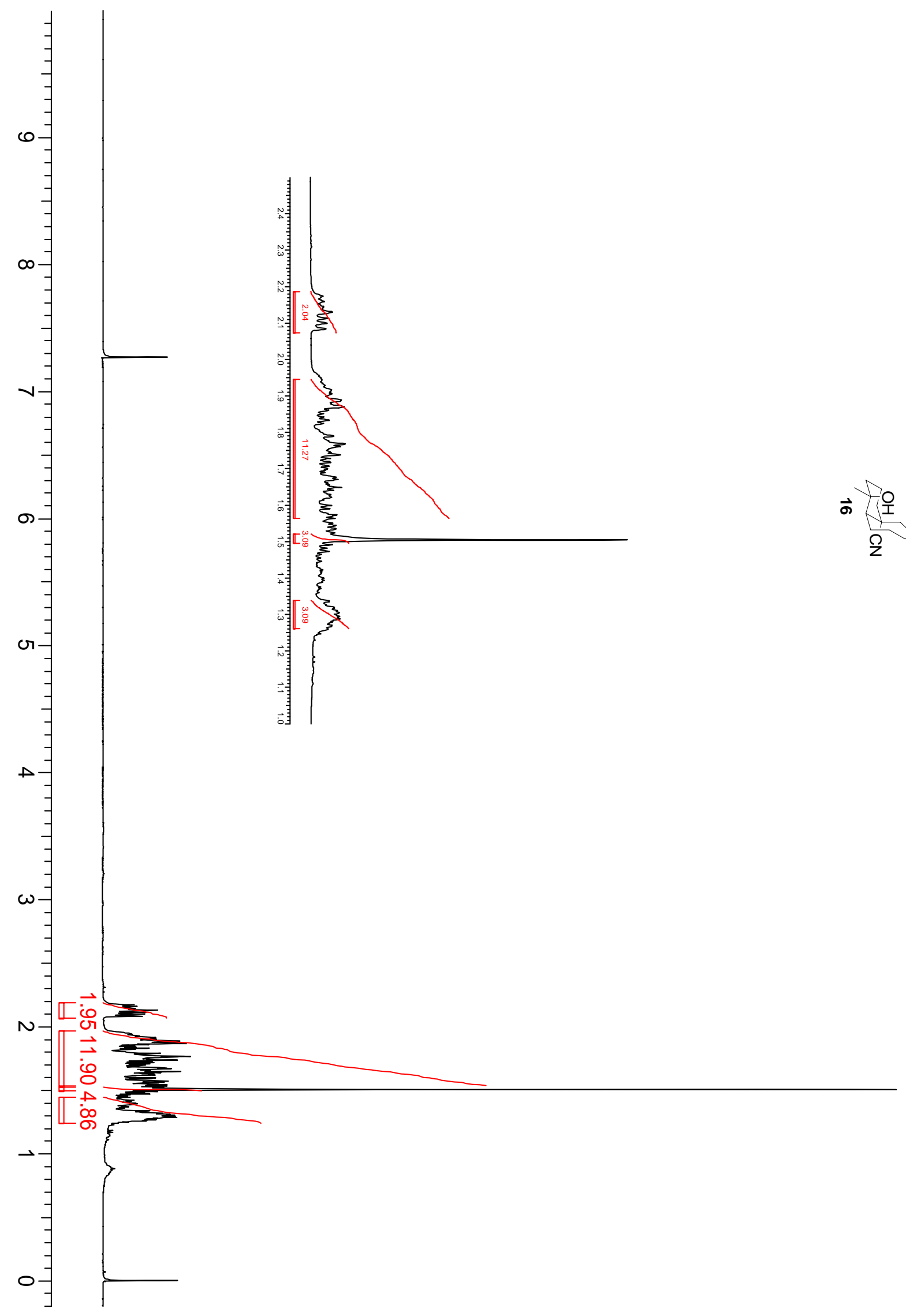




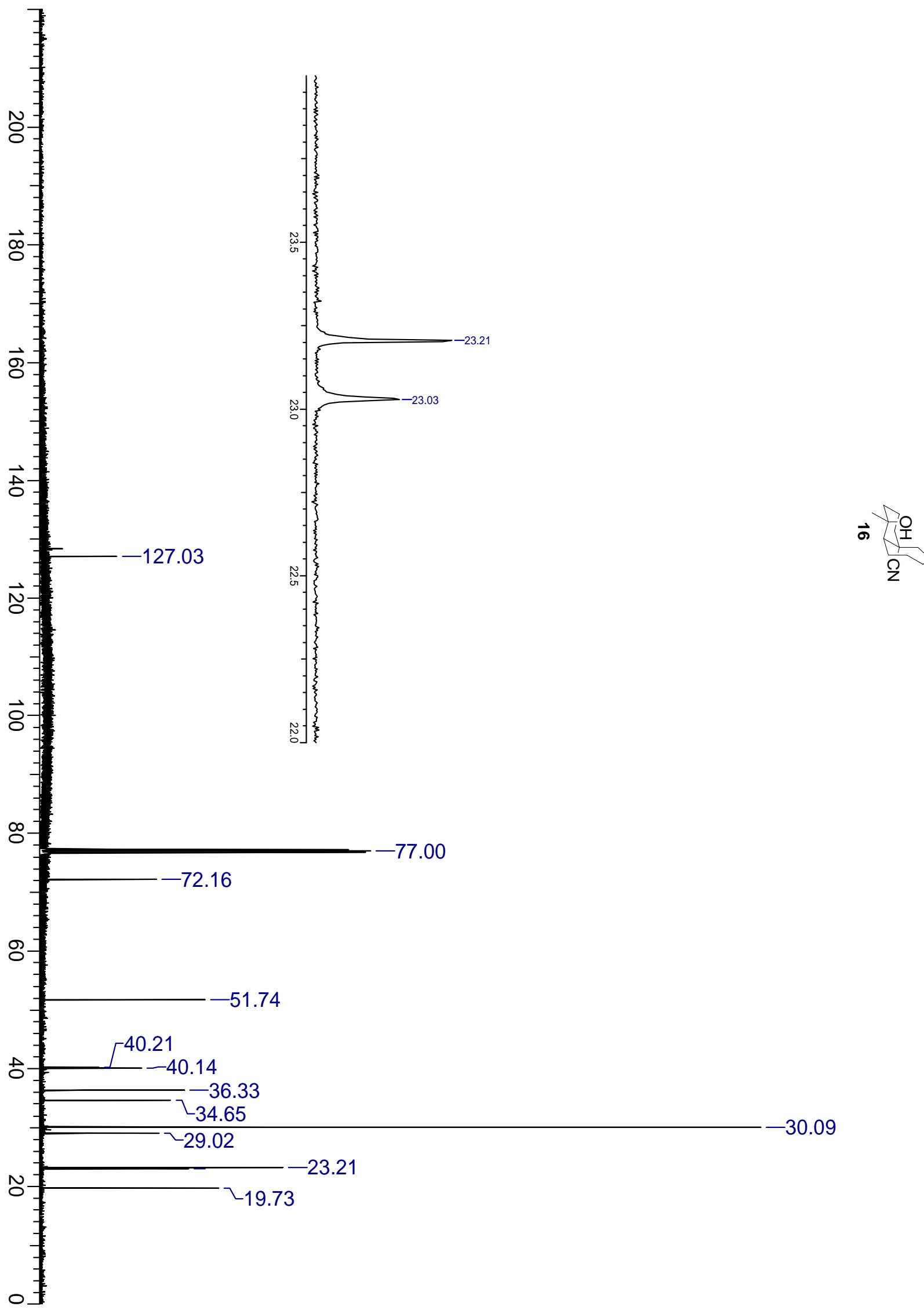




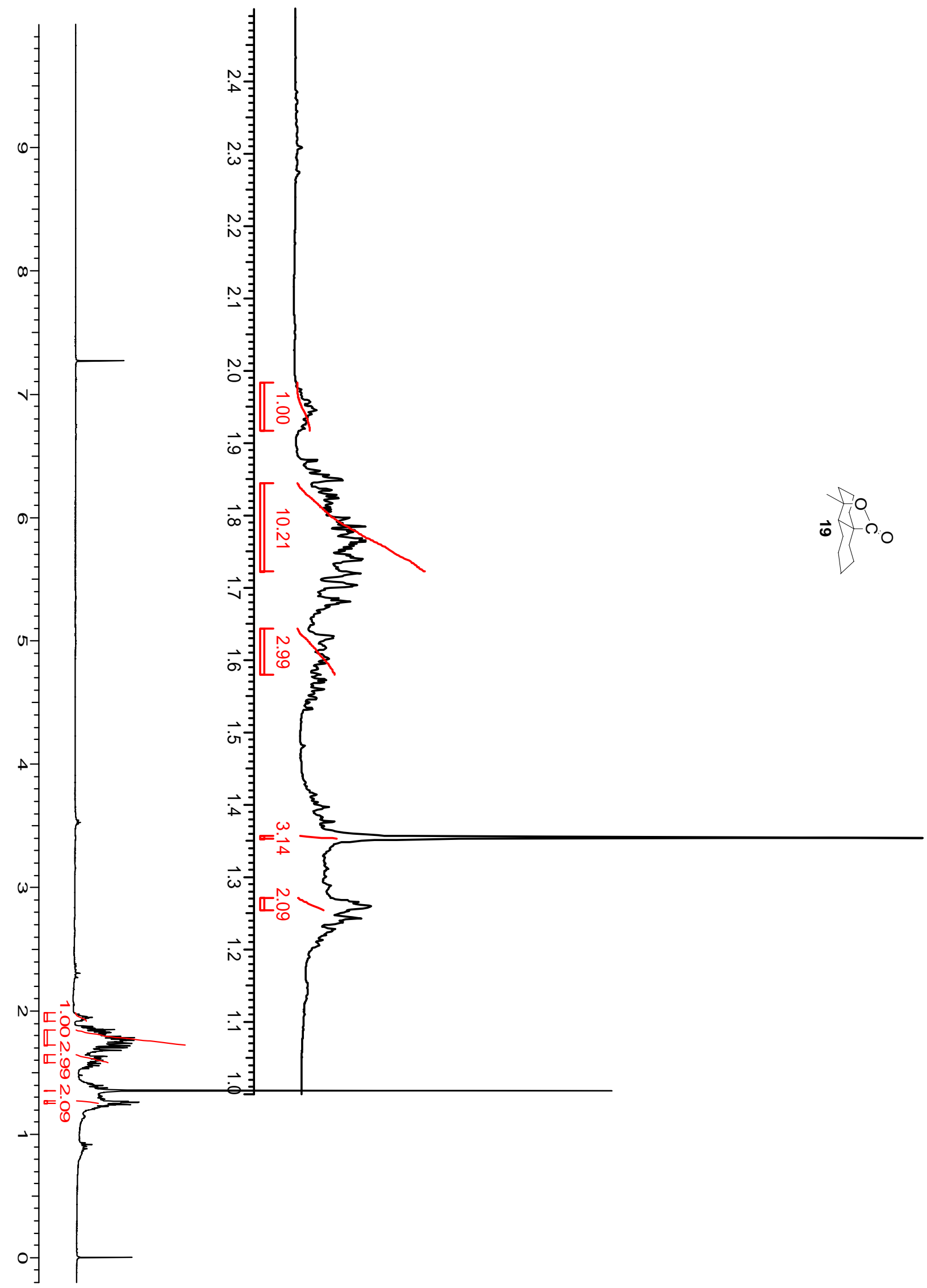




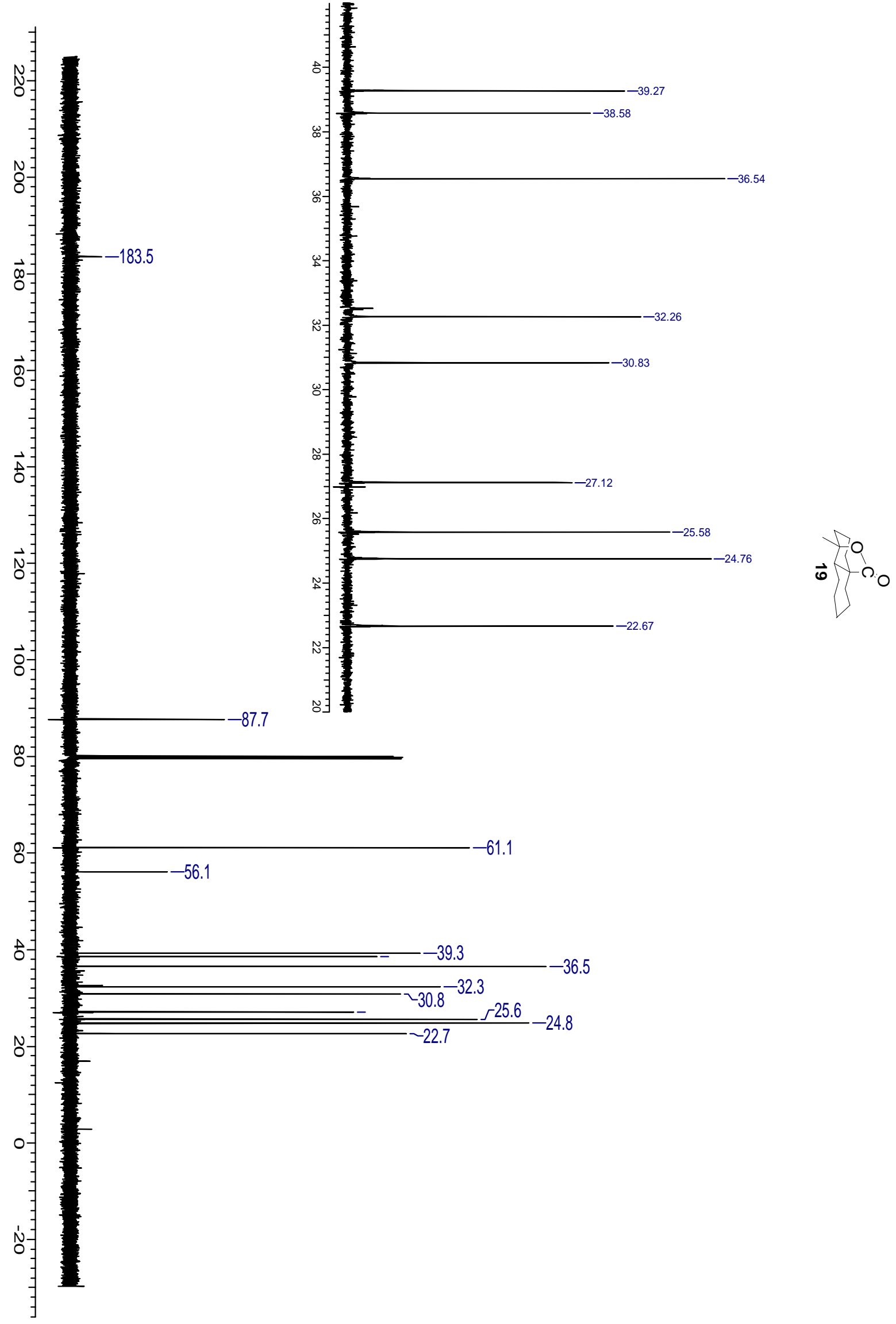



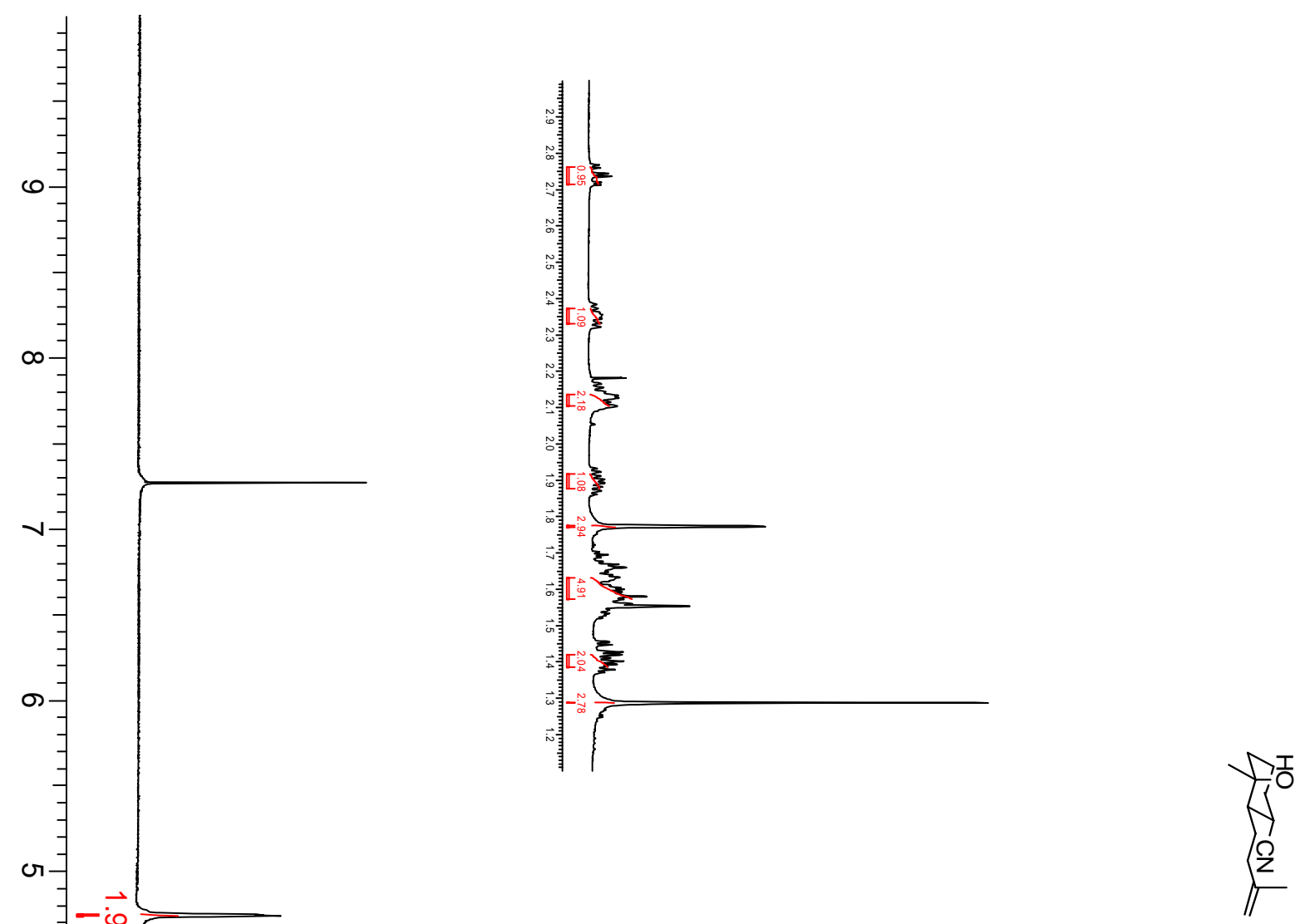

S21 


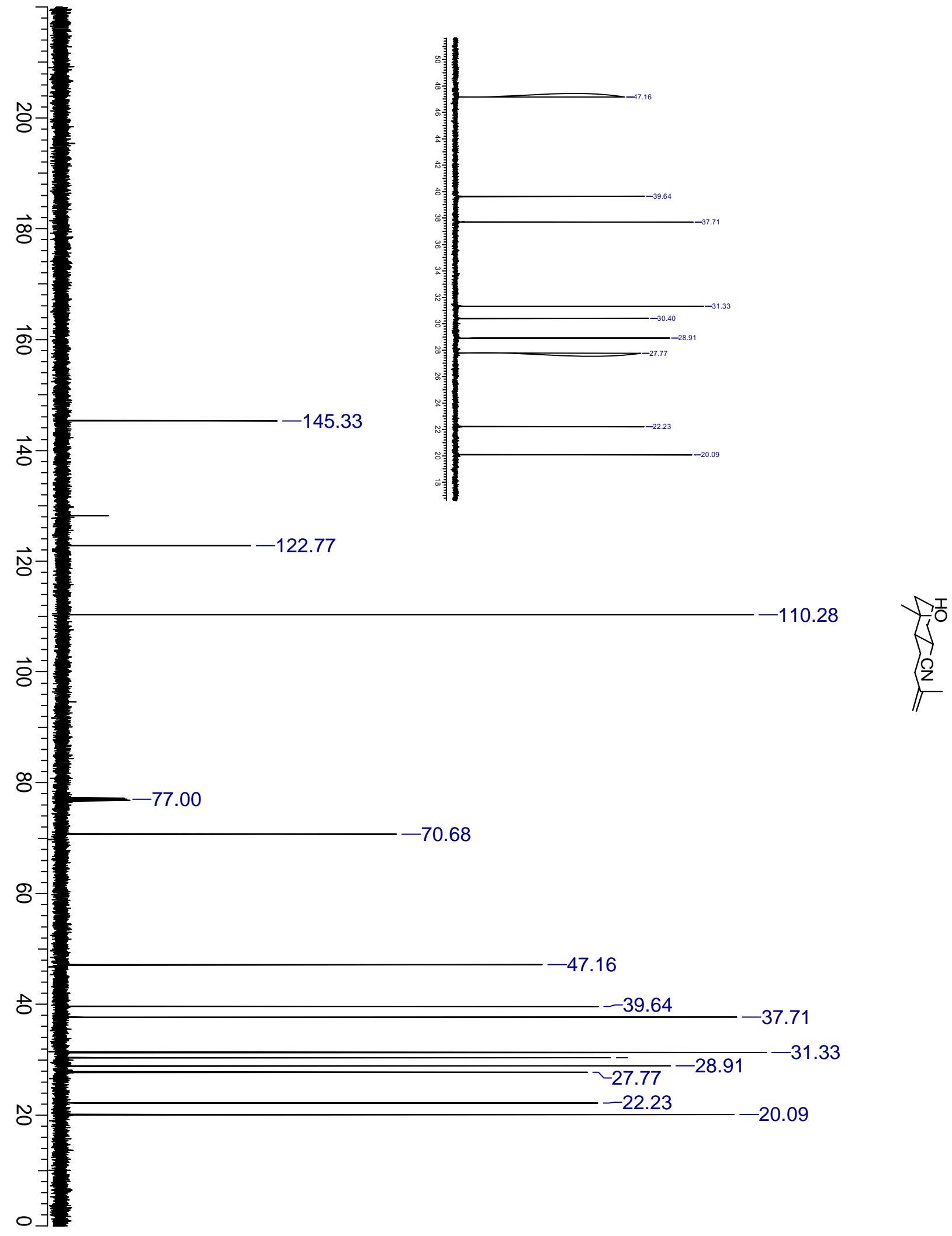




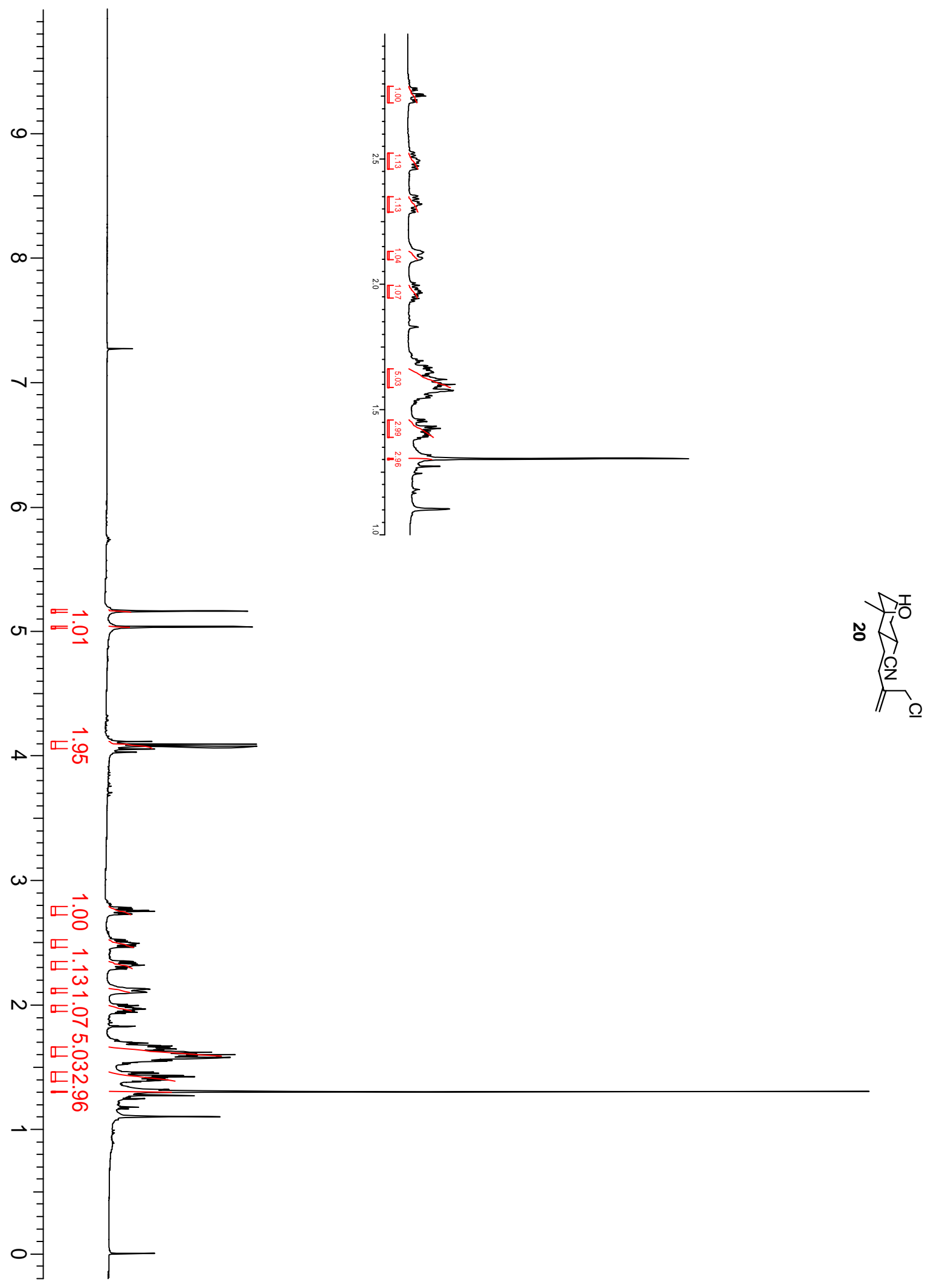




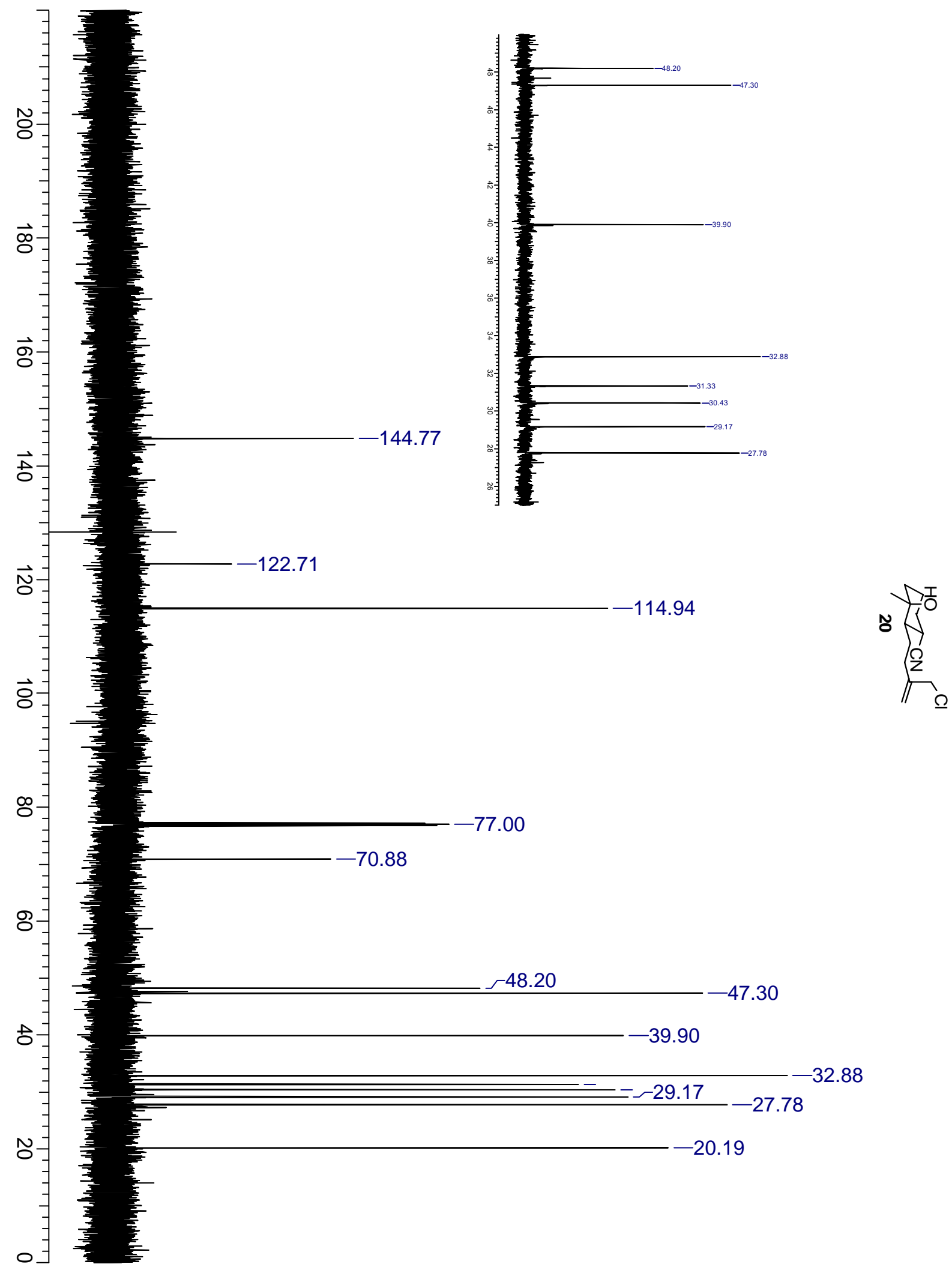




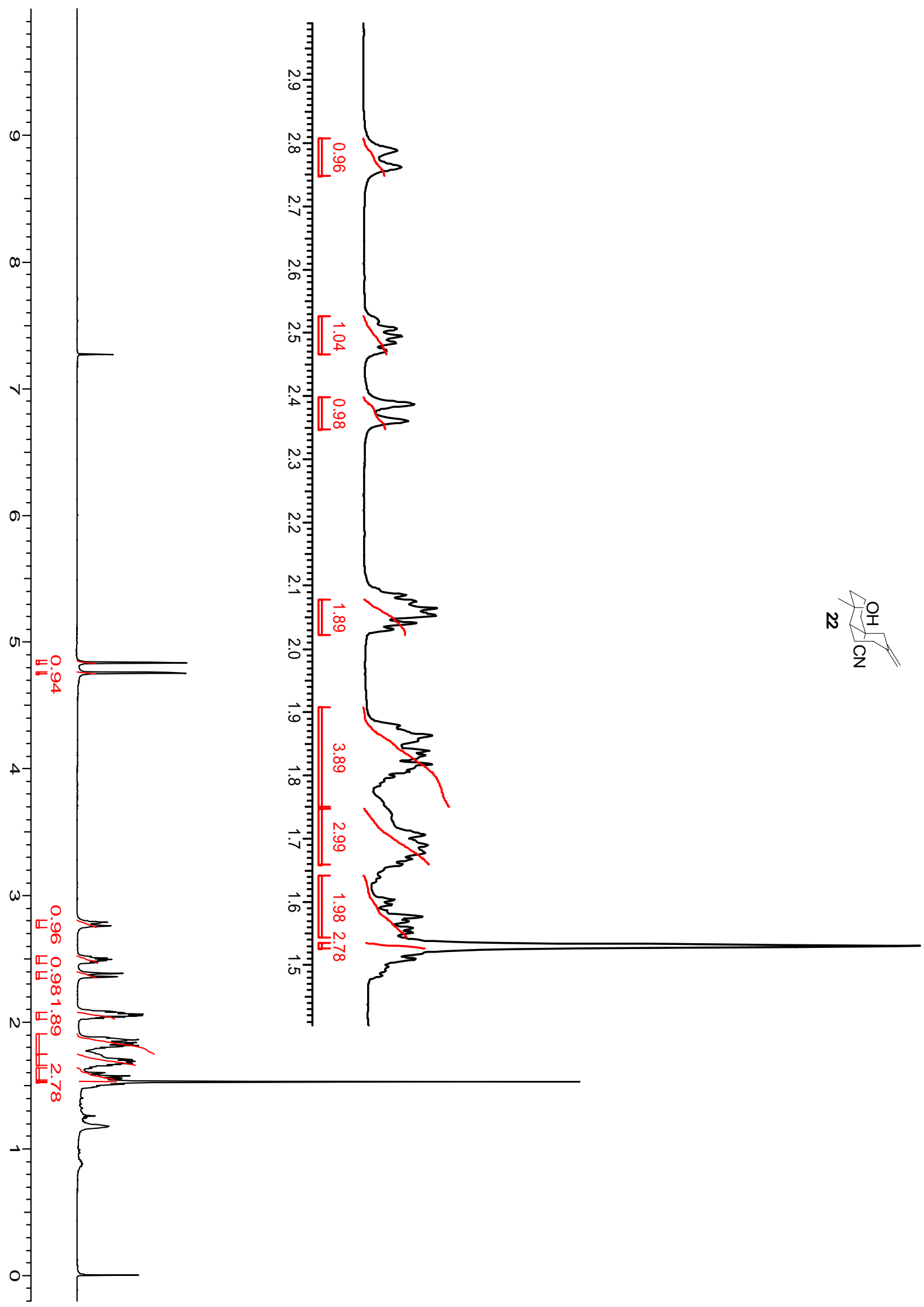




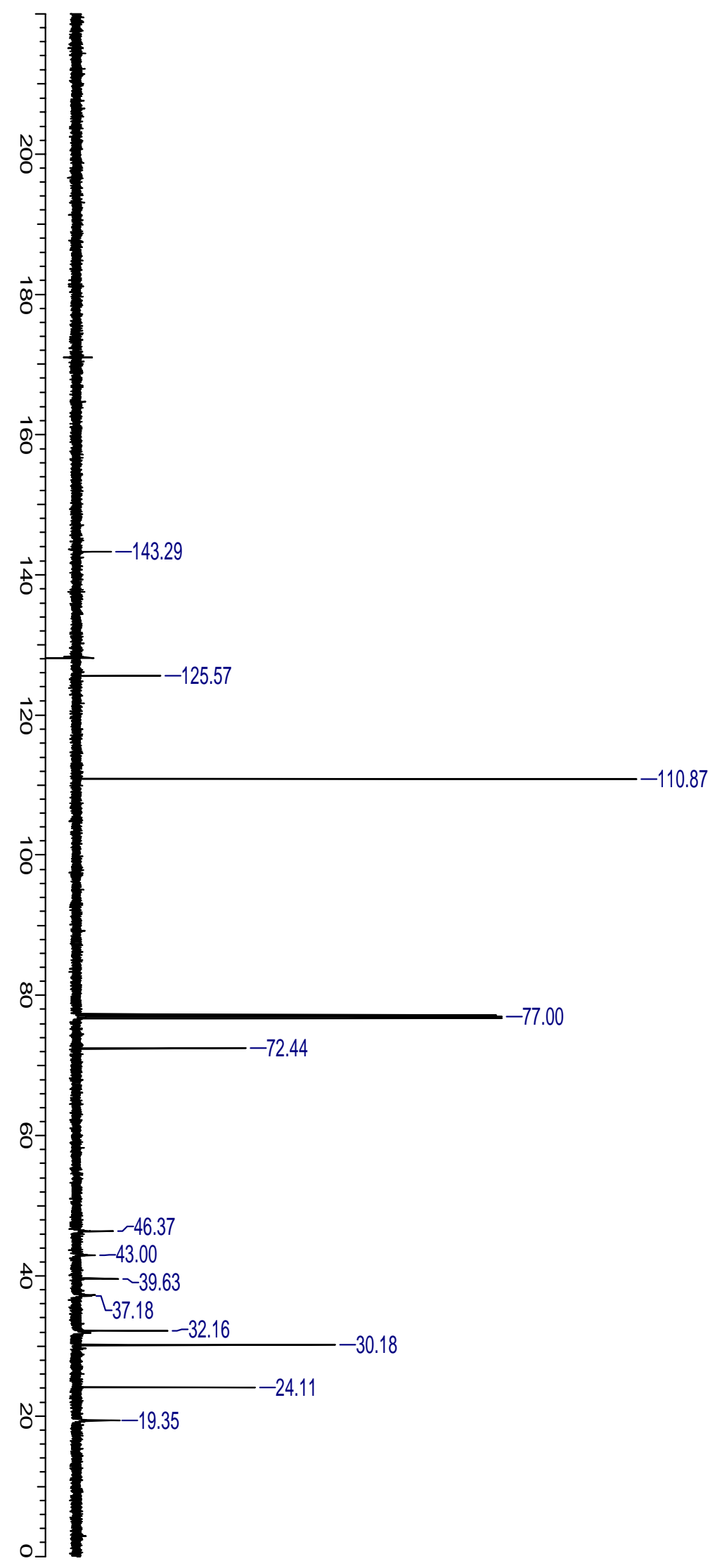




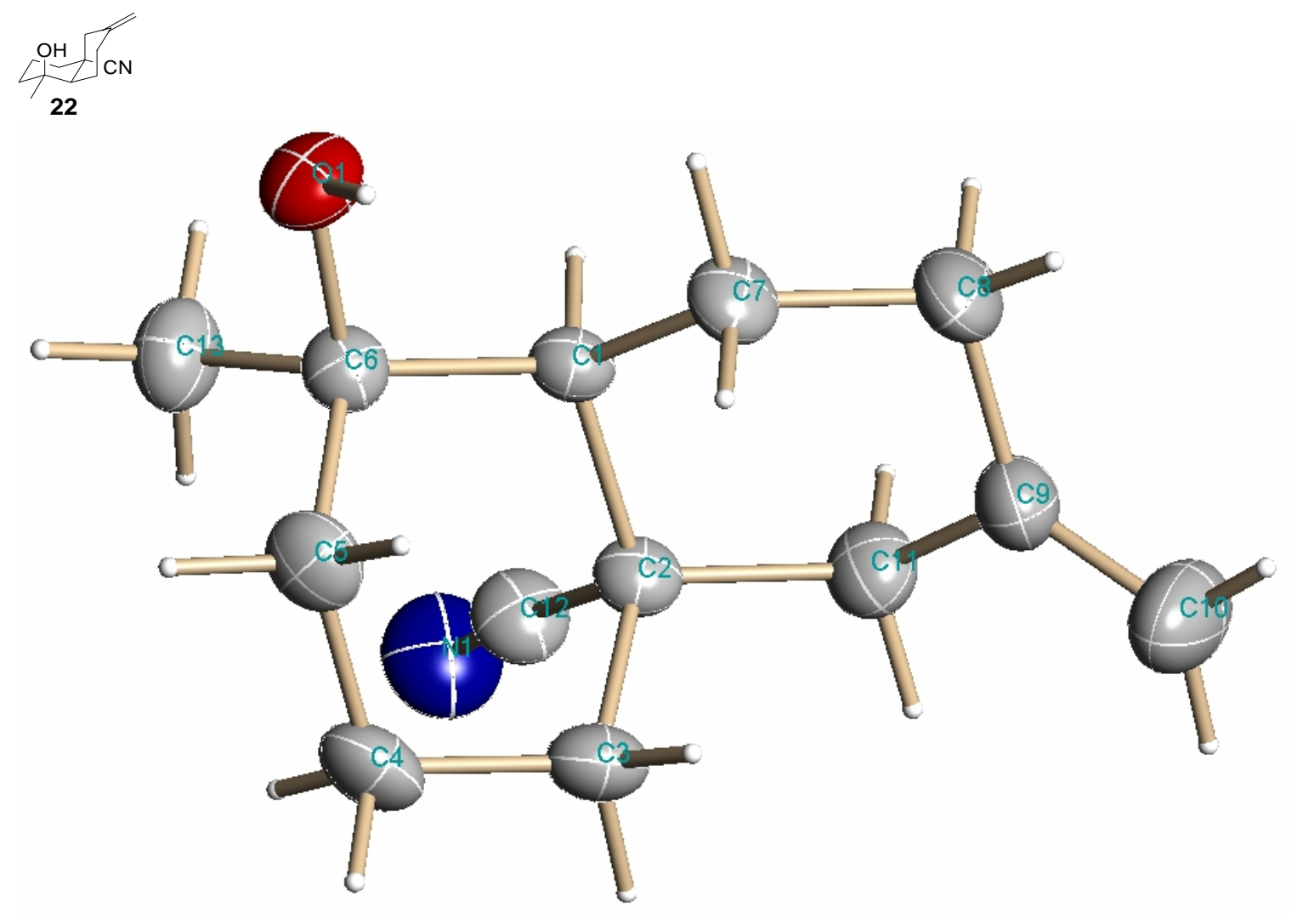




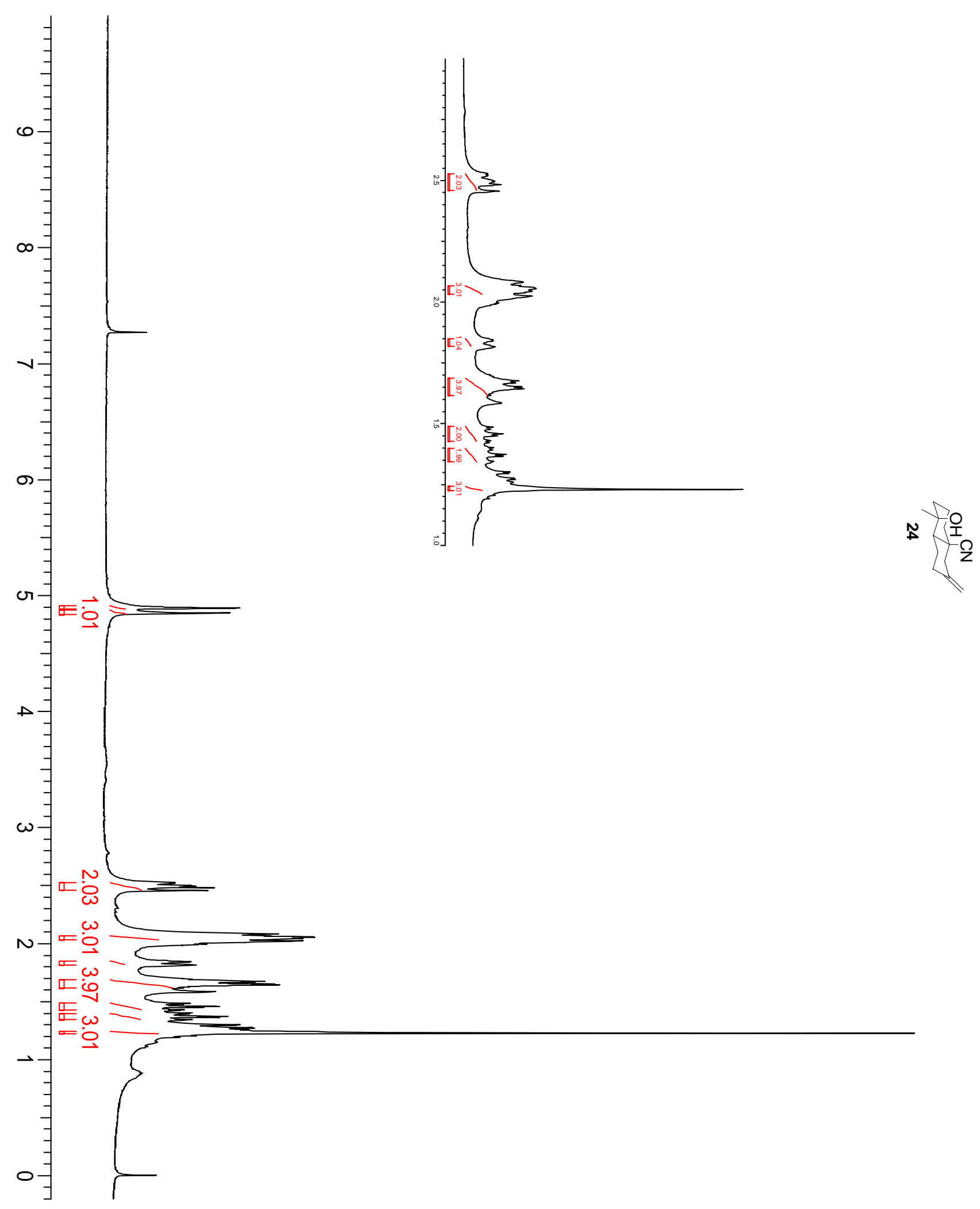

S28 


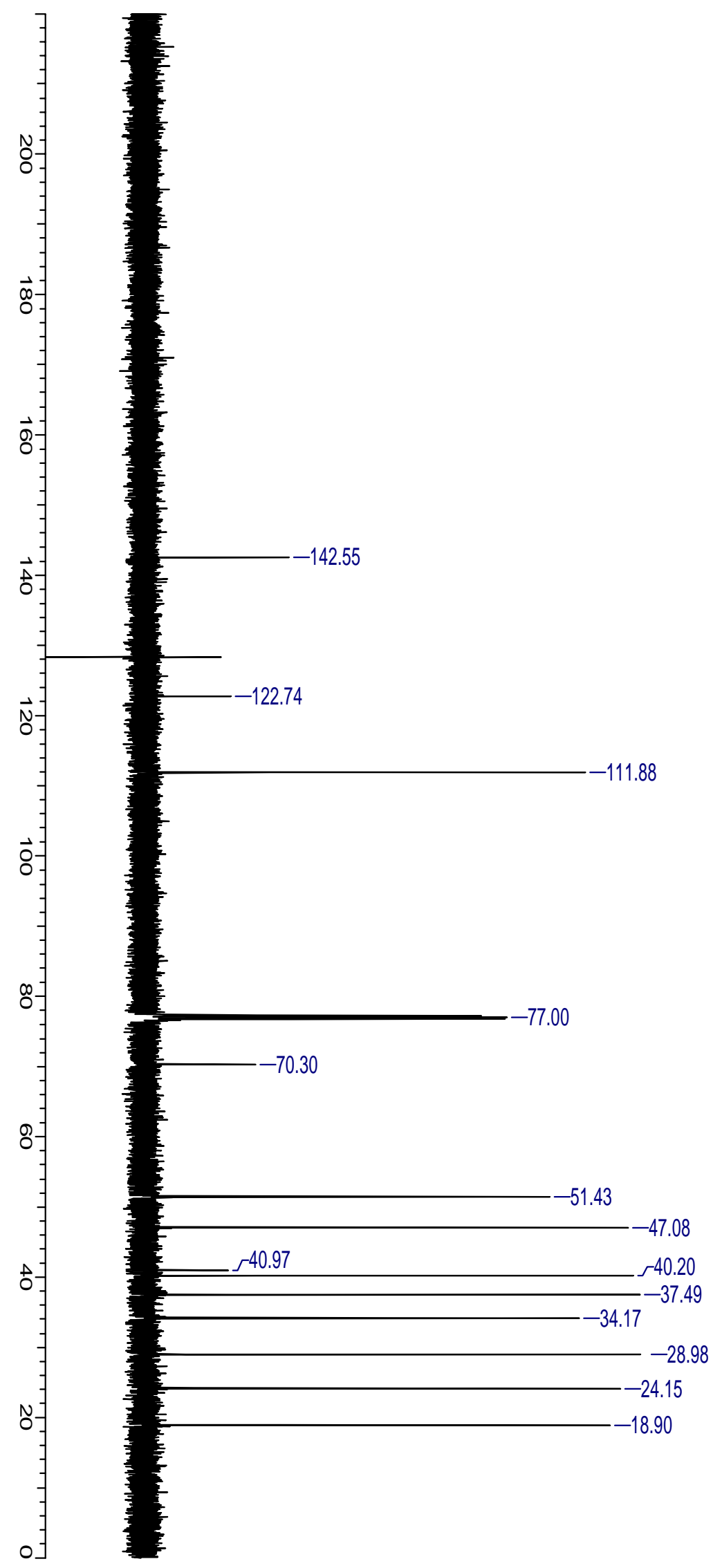

× $\frac{0}{1}$ 


\section{Reference:}

${ }^{1}$ Fleming F. F.; Zhang, Z.; Wang, Q.; Steward, O. W. J. Org. Chem. 2003, 68, 7646. 